\title{
A Petri Net Methodology for Modelling the Maintenance of Railway Route Sections
}

\author{
Jack Litherland \\ Resilience Engineering Research Group, University of Nottingham, United Kingdom \\ E-mail: jack.litherland1@nottingham.ac.uk \\ John Andrews \\ Resilience Engineering Research Group, University of Nottingham, United Kingdom \\ E-mail:.john.andrews@nottingham.ac.uk
}

Railway utilization is increasing. In 2017-18 there were over 1.7 billion passenger journeys made on the UK railway network, more than double the number made in 1995. Therefore getting maximum performance from the existing network by streamlining maintenance is vital. Previous research has tended to model maintenance interventions as uniform length and assume no spatial dependencies. However, in reality maintenance decisions are generally taken accounting for the condition of the whole of a route section thus prioritizing the utilization of the available resources. In this research, Petri nets will be used to explore a range of techniques for modelling maintenance on a 100 mile section of UK railway. Four methodologies will be implemented and compared. Initially the system will be modelled using a single small (220 yards) section and the values for the route section extrapolated from this. The second method will model the system as 849 individual small sections, with some interactions and dependencies considered between the track sections. The third methodology will consider that maintenance will affect a group of adjacent sections and maintenance will only be performed if all sections are degraded. The final methodology will schedule work using work banks to allow the number of sections maintained during an intervention to vary.

Keywords: Maintenance, Petri net, Railway, Stoneblowing, Tamping

\section{Introduction}

Overtime due to train loadings the alignment of ballasted rail track deteriorates. To rectify the deterioration maintenance interventions are performed to correct the alignment, nonetheless eventually the ballast will reach the end of its useful life and will need replacing. The cost of ballast maintenance interventions (such as tamping and stoneblowing) and ballast renewals are high, both in terms of monetary cost and the disruption to the railway. Therefore, deciding when to perform ballast interventions is an important decision for railway asset managers.

This paper presents four different Petri net models to simulate the deterioration and subsequent maintenance of a 100 mile section of the UK railway network. The models can be used by asset managers to plan maintenance interventions in such a way as to maximize ballast service life and minimize costs.

\section{Background}

There have been a range of models used to estimate the deterioration of ballast. AlvaHurtado and Selig (1981) proposed a logarithmic relationship between the number of loadings and permanent ballast strain, more recently Lichtberger (2007) proposed an exponential rate of deterioration and exponentially decreasing effectiveness of tamping. Following the observation of Selig and Water (1994) 'two identical sections of track, which have been used and maintained in exactly the same way, may exhibit completely different behaviors', there has been a move to use stochastic modelling techniques, such as Markov models (Shafahi and Hakhamaneshi 2009), Petri nets (Fecarotti and Andrews 2018) or even Bayesian networks (Mahboob 2014; Andrade and Teixeira 2015), to simulate the deterioration railway networks.

One of the limitations of the above methodologies is that interventions are modelled in a very homogenous way; during each intervention the length of track maintained is always the same. However analysis of Network Rail tamping records shows, for the UK railway network, this is not the case and the volume of track maintained and the effectiveness of the intervention can vary significantly. In this research a 100 mile section of UK railway was analyzed. This paper will present four methodologies to simulate the deterioration and maintenance of a 100 mile section of UK railway, the results were compared to historical maintenance records collected by Network Rail.

\section{The UK Railway}

The UK railway network comprises approximately 20,000 miles of track and in 20172018 over 1.7 billion passenger journeys were made on the network (Office of Road and Rail (UK) 2018). The majority of the UK network is constructed using ballasted track. Overtime the

Proceedings of the 29th European Safety and Reliability Conference.

Edited by Michael Beer and Enrico Zio

Copyright $(2019$ by ESREL2019 Organizers. Published by Research Publishing, Singapore

ISBN: 981-973-0000-00-0 :: doi: 10.3850/981-973-0000-00-0 esrel2019-paper 
condition of ballasted track deteriorates. There are a number of measures that can be used to assess the condition of ballasted track including; gauge, twist, cyclic top, horizontal alignment and vertical alignment (short-wave and long-wave). It is generally the vertical geometry (short-wave) measurements which is the most significant when deciding the condition of the track and the requirement for maintenance, although they all have acceptable tolerances (Andrews 2013).

In the UK the track alignment is recorded over 220 yards sections, using the New Measurement Train (see Figure 1). The frequency of the inspection is specified in Network Rail guidelines (Network Rail 2012) and is dependent on the track category, which is determined based on the line speed and equivalent million gross tonnage per annum. Following an inspection the section is placed into one of five quality bands based on the horizontal alignment, vertical alignment and line speed. These categories are 'Good', 'Satisfactory', 'Poor', 'Very Poor' and 'Super Red'.

If the track section alignment is found to be in one of the degraded states ('Satisfactory', 'Poor', 'Very Poor' or 'Super Red') then an intervention can be performed to improve the condition. There are a number of interventions that can be performed to improve the condition;

- Tamping; a typical tamping machine is selfpropelled and, by means of lifting and lining rollers that grip the head of the rail, is able to move the track to a pre-determined 'correct' position.

- Stoneblowing; stoneblowing is an alternative method to improve the alignment and is used considerably in the UK. During stoneblowing the sleepers are raised, small stones (fines) are blown under the sleepers and finally the sleepers are lowered. Stoneblowing is generally used to extend the life of fouled ballast. Stoneblowing cannot deliver as good an alignment as tamping and following a stoneblow it is bad practice to tamp the track.

- Manual Interventions; the track alignment can also be corrected manually, with handheld tools. Manual interventions are normally carried out when urgent maintenance is needed, as they can be implemented more quickly than stoneblowing or tamping.

- Cleaning; ballast cleaning is carried out using a ballast cleaning machine. The machine digs away ballast up to a minimum depth of $250 \mathrm{~mm}$ below the sleeper (Esveld 2001). The ballast that is dug out is then sieved and material smaller than $35 \mathrm{~mm}$ is filtered out. The cleaned material is then replaced along with new ballast to make up the deficiency.

- Ballast Renewal; ballast renewal removes the entire ballast layer and replaces it with new ballast. Ballast renewal will return the track geometry to 'Good' condition. During a ballast renewal the rails and sleepers are often also renewed.

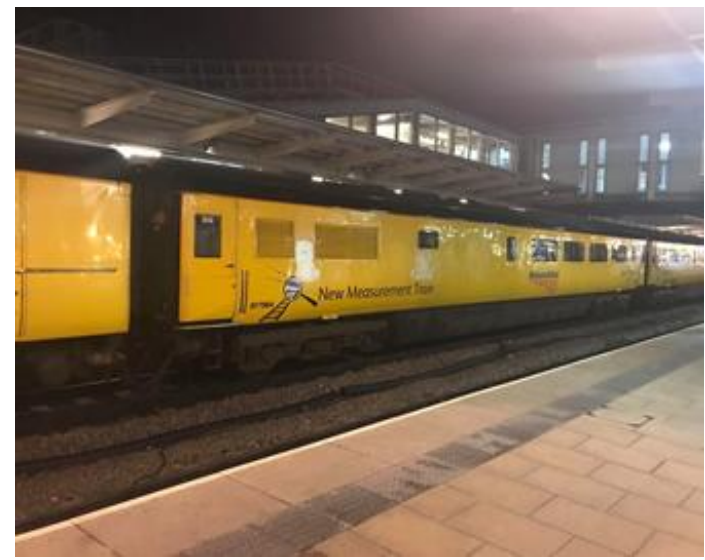

Fig. 1. New Measurement Train

\section{Data Analysis}

Network Rail's Ellipse database for Control Period Four (2009-2014) was analyzed to gain a better understanding of tamping and stoneblowing performed on the UK railway. The data was analyzed to determine the volume of tamping performed on the UK railway per year, the results are shown in Figure 2. It can be seen that there is a strong correlation between track category and the volume of tamping, on average $26.04 \%$ of category $1 \mathrm{~A}$ track was tamped each year, whereas only $4.99 \%$ of category six track was tamped each year.

More interesting results were discovered when the length of track tamped during interventions was investigated, see Figure 3. The analysis showed that although the mean length tamped remained similar for all track categories there was significant variation in the length tamped, with all categories being such that the standard deviation of the length tamped was greater than the mean (see Table 2). This suggests that to simulate tamping in the most effective way a model in which the length of track maintained during each intervention can be varied is required.

In addition to maintenance records, geometry records were also analyzed to determine the alignment prior to tamping, the results are shown in Table 1.

There are two possible reasons for the high percentage of track tamped despite being in 'Good' condition; 
(i) As the condition is assessed over 220 yards there may be a small piece within the 220 yard section that requires tamping but the overall condition is 'Good'.

(ii) Following discussions with Network Rail engineers it was suggested that when the alignment is close to entering 'Satisfactory' (but still in 'Good') it is tamped to stop it entering 'Satisfactory'.

Table 1. Condition prior to tamping

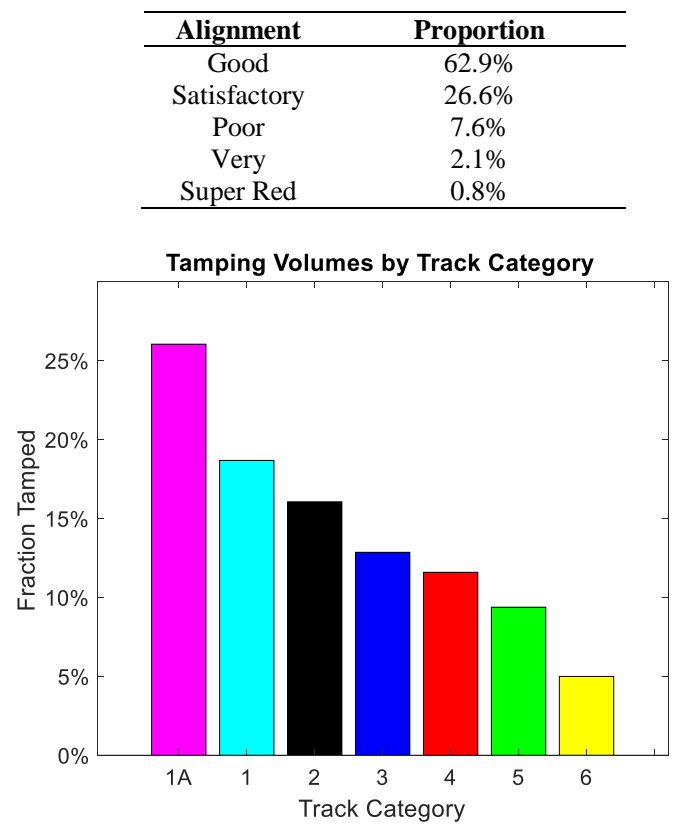

Fig. 2. Proportion of the UK network tamped per year by track category

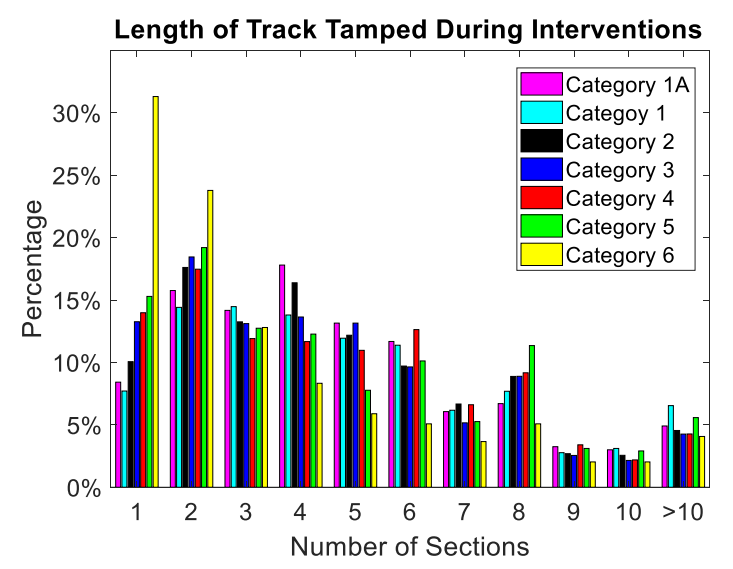

Fig. 3. The spread of the length tamped during an intervention
Table 2. Mean and standard deviation of the number of 220 yard sections tamped during an intervention (by track category).

\begin{tabular}{ccc}
\hline Category & Mean & Standard Deviation \\
\hline 1A & 5.204 & 7.147 \\
1 & 5.368 & 5.657 \\
2 & 4.963 & 4.560 \\
3 & 4.885 & 7.639 \\
4 & 5.344 & 9.640 \\
5 & 4.393 & 6.743 \\
6 & 4.234 & 10.087 \\
\hline
\end{tabular}

\section{Methodology}

In this research Petri nets (Petri 1962) are used to model the deterioration, inspection and maintenance of ballast. The first stage in the methodology was to create a model for a 220 yard section of railway. Four methodologies are then demonstrated to combine sections to determine the values for a 100 mile section of the UK network made up of 849, 220 yard sections.

In this research in addition to standard timed transitions (Murata 1989), conditional transitions and reset transitions (Andrews 2013) are used. Additionally in this research a new form of transition is proposed a conditional probabilistic transition, this is a combination of a conditional transition and probabilistic transition (D'souza 2017).

The conditional probabilistic transition has a set of input places $x_{i}$ with associated weights $X_{i}$, probability output places $y_{j}$ with associated probabilities $\check{y}_{j}$, cumulative probabilities $\check{z}_{j}$ and weights 1 . The $\check{y}_{j}$ are such that:

$$
\sum_{j=1}^{n} \check{y}_{j}=1
$$

The $\check{z}_{j}$ are such that:

$$
z_{j}=\sum_{i=1}^{j} \check{y}_{i}
$$

The values of $\breve{y}_{j}$ are dependent on a set of conditional places $C_{k}$.

Unlike a standard transition where all output places are marked when the transition fires only one of the $n$ output places is marked, the place marked is determined by the function $f(x)$ which is defined as;

$$
f(x)=j, s . t .\left\{\begin{array}{cc}
\check{Z}_{j-1} \leq x<\check{z}_{j} & x \geq \check{z}_{1} \\
j=1 & x<\check{z}_{1}
\end{array}\right.
$$

where $x \in[0,1)$ 
In addition to the set of output places $y_{j}$ there are also a set of constant output places $q_{v}$ with associated weights $Q_{v}$. These places are always marked when the transition fires. The transition can also be inhibited by a set of places $i_{w}$ with weights $I_{w}$. Figure 4 shows an example of a conditional probabilistic transition firing.

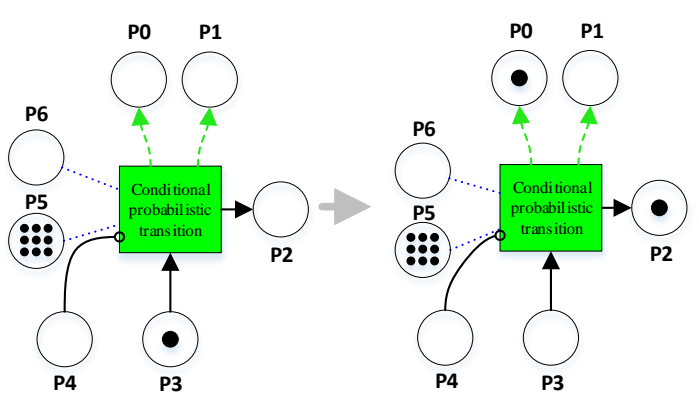

Fig. 4. Conditional probabilistic transition firing

\subsubsection{Yard Section Model}

The 220 yard section Petri net model is made up of four parts; deterioration, inspection, maintenance and renewal. The deterioration Petri net was created by connecting five places $\mathrm{P} 0 \rightarrow \mathrm{P} 4$ (one to model each of the five quality bands) and four conditional transitions $\mathrm{CT} 0 \rightarrow \mathrm{CT} 3$ in series as shown in Figure 5.

The places $\mathrm{P} 0 \rightarrow \mathrm{P} 4$ correspond to the track alignment. P0 corresponds to the best track alignment, 'Good' and P4 corresponds to the worst 'Super Red'. Overtime the conditional transitions $\mathrm{CT} 0 \rightarrow \mathrm{CT} 3$ fire simulating the track alignment deteriorating. The firing times of conditional transitions CT0 $\rightarrow$ CT3 were sampled from Weibull distributions. The distributions used were based on those observed by Audley and Andrews (2013) and are shown in Appendix A. The Weibull scale parameters were adjusted based on the number of previous interventions (tamps and stoneblows) and the track category. Figure 6 shows the deterioration profile for category 1A track, if no maintenance is performed, after 50 years there is close to unity probability of the ballast having reached the 'Super Red' condition.

The alignment of the track is only known following an inspection performed by the New Measurement Train (see Figure 1). To model this each of the degraded condition places $(\mathrm{P} 1 \rightarrow \mathrm{P} 4)$ are linked to subsequent revealed degradation places via timed transitions. These transitions are only enabled when an inspection is ongoing, the frequency of inspection was chosen based on the values given in standards (Network Rail 2012). Following degradation being revealed a conditional probabilistic transition decides whether the track alignment should be corrected by tamping or stoneblowing, based on the number of previous interventions. Three rules were considered;

(i) Tamping is performed approximately three times as often as stoneblowing (Category $1 \rightarrow 6$ )

(ii) For category $1 \mathrm{~A}$ track stoneblowing is only considered after eight tamps (Tamping is the preferred method for category $1 \mathrm{~A}$ track as stoneblowing cannot deliver the required alignment)

(iii) Following a stoneblow it is bad practice to tamp the section

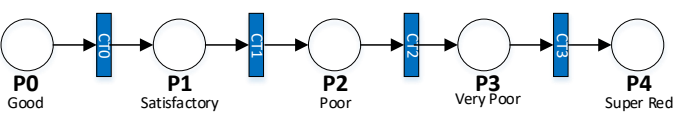

Fig. 5. Deterioration Petri Net

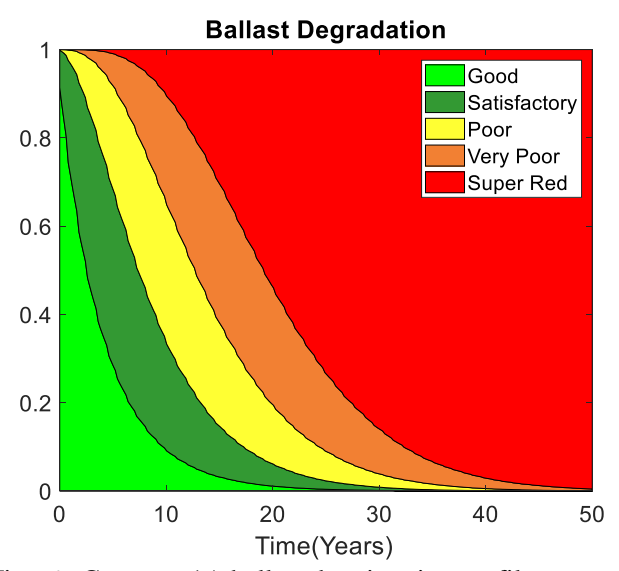

Fig. 6. Category 1A ballast deterioration profile (maintenance not considered)

Maintenance records were analyzed to determine distributions for the schedule time; the time between maintenance being requested (raised date) and maintenance being carried out (complete date). The data was split into two groups; 'routine schedule time' if the alignment was in 'Good', 'Satisfactory' or 'Poor' at the time of maintenance being requested and 'emergency schedule time' if the alignment was 'Very Poor' or 'Super Red' at the time of maintenance being requested.

Reset transitions are used to simulate an intervention taking place. The firing of the reset transitions were sampled from a lognormal distributions whose parameters were estimated based on the maintenance records. When a reset transition fires the system is reset to its original marking (no deterioration and no maintenance 
requested). The marking of the places used to record the number of tamps, number of stoneblows and total number of interventions (P21) are not altered by the reset transition, instead the marking of the appropriate place is increased by one based on the type of maintenance that was performed. The marking of these places is only reset following a renewal or clean.

Following a maintenance intervention the ballast will not always be returned to the 'Good' condition therefore, following the firing of the reset transition, a conditional probabilistic transition is used to update the alignment to either 'Good', 'Satisfactory' or 'Poor' based on the number of previous intervention. It is assumed that the effectiveness of interventions decreases as more are performed.

Ballast cleaning and ballast renewal was scheduled based on the number of maintenance interventions that had taken place previously, the part of the Petri net used to model this is shown in Figure 7. After the section has been tamped six times a clean would be requested, note that due to the limited number of cleaners, it can be over a year between a cleaner being requested and the clean being completed, therefore tamping and stoneblowing can still be performed even if the section is scheduled to be cleaned or renewed. Following a clean the marking of P21 (number of passed interventions) is set to two (to model the fact that cleaning is not as effective as a full renewal). The inhibitor arcs between places P27 and transitions T13 and T14 ensure that only one clean is permitted in the ballast's lifetime.

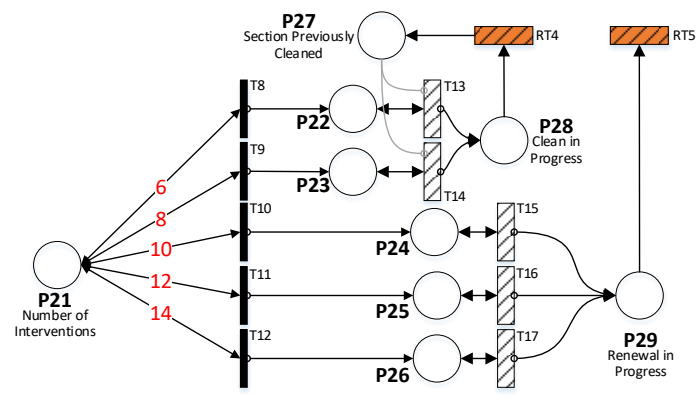

Fig. 7. Petri net used to schedule cleaning and renewal based on past interventions

The final maintenance intervention considered is manual interventions. Manual interventions are assumed to be carried out if the alignment is known to be 'Very Poor' or 'Super Red' and returns the condition to 'Poor', manual interventions are scheduled much more quickly than tamping or stoneblowing.

The final aspect of the single track section model considers safety and risk. If the ballast is known to be in the 'Very Poor' or 'Super Red' condition it is assumed to no longer be safe to run trains at line speed and a temporary speed restriction has to be imposed. If a speed restriction is imposed the capacity of the route decreases and this will cause train delays and there are costs associated with this. The highest risk of derailment occurs if the track alignment is in the 'Very Poor' or 'Super Red' condition but has not been detected, the number of days this occurs is recorded and a cost assigned to it.

The single track section Petri net was simulated using bespoke $\mathrm{C}++$ code. The single track section Petri net model was simulated 100,000 times for a 50 year period. Tables $3 \rightarrow 6$, summarize the key outputs of the model for a category 1A track section; the number of interventions, the number of days with a speed restriction, the number of days the alignment was undetected in the 'Very Poor' or 'Super Red' condition and the overall cost. Figure 8 shows the convergence of the total cost, number of tamps and number of stoneblows.
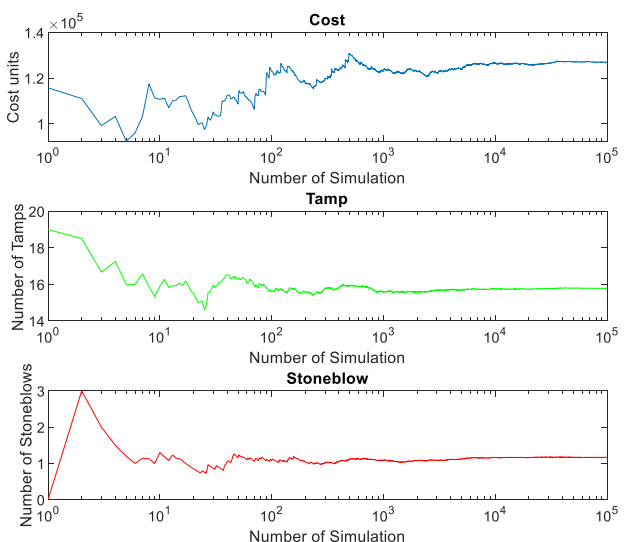

Fig. 8. Convergence of the total cost, number of tamps and number of stoneblows (Category 1A track section, log scale)

Table 3. Number of interventions over 50 years (Category 1A track section) ${ }^{a}$

\begin{tabular}{cccccc}
\hline Intervention & Mean & $\begin{array}{c}\% \\
\text { per } \\
\text { year }\end{array}$ & $\sigma$ & Max. & Min. \\
\hline Tamp & 15.82 & 31.54 & 5.21 & 44 & 1 \\
Stoneblow & 1.20 & 2.33 & 1.88 & 12 & 0 \\
Clean & 1.14 & 2.28 & 0.48 & 4 & 0 \\
\hline
\end{tabular}

\footnotetext{
a $\%$ is the average volume tamped per year for comparison to the data shown in Figure 2 and $\sigma$ is the standard deviation.
} 
Table 4. Percentage of time undetected ballast deterioration occurs over 50 years (Category $1 \mathrm{~A}$ track section)

\begin{tabular}{cccc}
\hline $\begin{array}{c}\text { Unrevealed } \\
\text { condition }\end{array}$ & Mean & Max. & Min. \\
\hline Very Poor & $0.026 \%$ & $0.329 \%$ & $0 \%$ \\
Super Red & $1.2 \times 10^{-4} \%$ & $0.323 \%$ & $0 \%$ \\
\hline
\end{tabular}

Table 5. Percentage of time speed restrictions are imposed over 50 years (Category 1A track section)

\begin{tabular}{cccc}
\hline $\begin{array}{c}\text { Speed } \\
\text { Restriction }\end{array}$ & Mean & Max. & Min. \\
\hline $\begin{array}{c}\text { No Speed } \\
\text { Restriction } \\
\text { Very Poor } \\
(\text { Level 1) }\end{array}$ & $99.988 \%$ & $100 \%$ & $98.783 \%$ \\
$\begin{array}{c}\text { Super Red } \\
(\text { Level 2) }\end{array}$ & $3.7 \times 10^{-5} \%$ & $0.225 \%$ & $0 \%$ \\
\hline
\end{tabular}

Table 6. Overall cost in 50 years (Category $1 \mathrm{~A}$ track section)

\begin{tabular}{cccc}
\hline Cost & Mean & Max. & Min. \\
\hline $\begin{array}{c}\text { Total Cost } \\
\text { Unit }\end{array}$ & 127,000 & $6,417,000$ & 13,000 \\
\hline
\end{tabular}

\subsection{Route Model}

The main aim of this research is to explore, how the model for the 220 yard track section can be expanded to form a system model. The remainder of this paper addresses this. In this research Bletchley Delivery Unit, a section of railway on the UK network was used as a case study. The route contains approximately 100 miles of track made up of 849,220 yard sections. The route is made up of a range of track categories; 484 category 1A, 60 category 1,170 category 2, 6 category 3 and 129 category 5 . At this stage no consideration is given to multiple running lines.

Four methodologies will be considered to model the route. The following sections summarize the methodology and Tables $7 \rightarrow 12$ summarize the number of interventions and speed restrictions.

\subsubsection{Methodology 1: Extrapolation}

The first method considers just extrapolating the results of the single track section model to determine the route parameters. The results are calculated as;

$$
\sum_{i=0}^{6} \theta_{i} r_{i}
$$

where $\theta_{i}$ is the number of category $i$ sections and $r_{i}$, is the result of interest for category $i$. Note $\theta_{0}$ and $r_{0}$ are used to denote category $1 \mathrm{~A}$ track.

\subsubsection{Methodology 2: Individual Models with} Opportunistic Maintenance

In the second methodology each 220 yard section is modelled with its own Petri net simultaneously under the control of a master module. The master module was used to queue maintenance based on the number of tampers and stoneblowers that were available, there are assumed to be six tampers and three stoneblowers, the master module is used to ensure that a maximum of six sections can be tamped at a time. Additionally when a section was tamped/stoneblowned the condition of the neighboring sections were checked and work would be performed on the neighboring sections too, if any degradation was present.

\subsubsection{Methodology 3: Individual Models and} Block Maintenance

The third methodology also contained 849 track section modules under the control of a master module, however based on the observation that during a tamp or stoneblow on average five 220 yard sections were maintained, the model was adapted such that routine maintenance (From 'Satisfactory' or 'Poor' condition) would only be performed when a block of five adjacent sections were degraded. Emergency maintenance (if a section was in 'Very Poor' or 'Super Red') was still be performed on an individual bases.

\subsubsection{Methodology 4: Individual Models with Work Banks}

The final methodology again simulated the route as 849 track section modules under the control of a master module. However the fourth methodology aims to take account of three additional features;

(i) The variation in the length tamped observed in Figure 3.

(ii) The observation that a high number of sections were tamped despite being in 'Good' condition (this was observed in the data and verified by Network Rail engineers).

(iii) Priorities areas with the worst deterioration

In the fourth methodology the scheduling of maintenance is done using work banks. Each of the 849 track sections are given a score according to;

$$
s=k \cdot \frac{\alpha}{\beta},
$$

where $k$ is the time since the condition was last improved, $\alpha$ is a scaling factor based on the 
quality band ('Good', 'Satisfactory' etc.) and $\beta$ is a scaling factor based on the track category (1A, 1, etc.). A work bank is generated based on the scores, $s$.

Initially batches of ten adjacent sections are considered, the scores of all ten sections are added together to determine an overall batch score, $S$. If $S$ is greater than a threshold, $\delta_{i}$, then all ten sections are placed in the work bank. The process is then repeated with batches of decreasing length, from nine to one. A record is kept of which sections have been added to the work bank to ensure the same section cannot be added twice.

The work bank is re-evaluated every 73 days, this value was initially chosen based on engineering judgement.

Table 7. Average number of tamps in 50 years; comparison of methodologies

\begin{tabular}{cccccc}
\hline & \multicolumn{5}{c}{ Methodology } \\
\hline Category & Data & 1 & 2 & 3 & 4 \\
\hline 1A & 13.02 & 15.82 & 36.75 & 17.73 & 37.04 \\
1 & 9.34 & 12.38 & 15.72 & 7.74 & 13.69 \\
2 & 8.03 & 11.11 & 10.99 & 5.52 & 12.96 \\
3 & 6.43 & 8.32 & 12.16 & 5.43 & 11.08 \\
4 & 5.80 & 6.21 & $\mathrm{n} / \mathrm{a}$ & $\mathrm{n} / \mathrm{a}$ & $\mathrm{n} / \mathrm{a}$ \\
5 & 4.69 & 4.65 & 4.04 & 1.89 & 6.65 \\
\hline
\end{tabular}

Table 8 . Average number of stoneblows in 50 years; comparison of methodologies

\begin{tabular}{cccccc}
\hline & \multicolumn{5}{c}{ Methodology } \\
\hline Category & Data & 1 & 2 & 3 & 4 \\
\hline $1 \mathrm{~A}$ & 2.48 & 1.20 & 8.89 & 0.02 & 7.41 \\
1 & 4.60 & 4.38 & 6.34 & 0.04 & 1.48 \\
2 & 4.26 & 3.98 & 3.56 & 0.01 & 1.26 \\
3 & 2.44 & 3.44 & 6.30 & 0.04 & 0.86 \\
4 & 1.75 & 2.86 & $\mathrm{n} / \mathrm{a}$ & $\mathrm{n} / \mathrm{a}$ & $\mathrm{n} / \mathrm{a}$ \\
5 & 1.23 & 1.68 & 0.66 & $4.7 \times 10^{-4}$ & 0.30 \\
\hline
\end{tabular}

Table 9. Average number of cleans in 50 years; comparison of methodologies

\begin{tabular}{ccccc}
\hline \multicolumn{5}{c}{ Methodology } \\
\hline Category & 1 & 2 & 3 & 4 \\
\hline 1A & 1.14 & 1.46 & 1.17 & 1.49 \\
1 & 1.13 & 0.65 & 0.28 & 0.68 \\
2 & 1.04 & 0.32 & 0.13 & 0.48 \\
3 & 0.76 & 0.27 & 0.13 & 0.12 \\
4 & 0.38 & $\mathrm{n} / \mathrm{a}$ & $\mathrm{n} / \mathrm{a}$ & $\mathrm{n} / \mathrm{a}$ \\
5 & 0.16 & $4.1 \times 10^{-3}$ & 0.01 & $2.9 \times 10^{-3}$ \\
\hline
\end{tabular}

Table 10. Average number of renewals in 50 years; comparison of methodologies

\begin{tabular}{ccccc}
\hline \multicolumn{5}{c}{ Methodology } \\
\hline Category & 1 & 2 & 3 & 4 \\
\hline $1 \mathrm{~A}$ & 0.76 & 0.94 & 0.07 & 0.83 \\
1 & 0.78 & 0.34 & $1.1 \times 10^{-3}$ & 0.01 \\
2 & 0.67 & 0.14 & $6.8 \times 10^{-4}$ & 0.01 \\
3 & 0.49 & 0.16 & $4.4 \times 10^{-3}$ & $1.2 \times 10^{-3}$ \\
4 & 0.24 & $\mathrm{n} / \mathrm{a}$ & $\mathrm{n} / \mathrm{a}$ & $\mathrm{n} / \mathrm{a}$ \\
5 & 0.08 & 0 & $3.3 \times 10^{-5}$ & 0 \\
\hline
\end{tabular}

Table 11. Number of days with a level 1 speed restriction in 50 years; comparison of methodologies

\begin{tabular}{ccccc}
\hline \multicolumn{5}{c}{ Methodology } \\
\hline Category & 1 & 2 & 3 & 4 \\
\hline $1 \mathrm{~A}$ & 4.57 & 2.08 & 3.82 & 10.77 \\
1 & 5.98 & $4.7 \times 10^{-3}$ & 0.08 & 0.06 \\
2 & 5.58 & $8.1 \times 10^{-4}$ & $3.8 \times 10^{-3}$ & $2.8 \times 10^{-3}$ \\
3 & 8.61 & 0 & $7.5 \times 10^{-4}$ & $8.3 \times 10^{-5}$ \\
4 & 18.65 & $\mathrm{n} / \mathrm{a}$ & $\mathrm{n} / \mathrm{a}$ & $\mathrm{n} / \mathrm{a}$ \\
5 & 5.99 & 0 & $3.9 \times 10^{-6}$ & 0 \\
\hline
\end{tabular}

Table 12. Number of days with a level 2 speed restriction in 50 years; comparison of methodologies

\begin{tabular}{ccccc}
\hline \multicolumn{5}{c}{ Methodology } \\
\hline Category & 1 & 2 & 3 & 4 \\
\hline $1 \mathrm{~A}$ & 0.02 & 0.01 & $2.9 \times 10^{-3}$ & 0.05 \\
1 & 0.04 & $8.3 \times 10^{-6}$ & $1.7 \times 10^{-5}$ & $1.1 \times 10^{-4}$ \\
2 & 0.05 & 0 & $5.8 \times 10^{-6}$ & $8.8 \times 10^{-6}$ \\
3 & 0.06 & 0 & 0 & 0 \\
4 & 0.13 & $\mathrm{n} / \mathrm{a}$ & $\mathrm{n} / \mathrm{a}$ & $\mathrm{n} / \mathrm{a}$ \\
5 & 0.03 & 0 & 0 & 0 \\
\hline
\end{tabular}

\section{Discussion and Conclusions}

Analysis of Network Rail data revealed that there was significant variation in the length of track maintained during interventions and that interventions were often performed even if the section was already in 'Good' condition. This paper presented a Petri net for a 220 yards section of railway and then explored four methodologies to combine the single 220 yard section model to form a route model.

The first method considered was a simple extrapolation of the 220 yard section model. This method was the fastest to compute but its inability to consider any dependencies between sections made it unrealistic.

The second methodology considered modelling the sections individually; thus enabling individual characteristics of each section (such as track category) to be considered. This methodology led to an increase in the number of interventions caused by the consideration of opportunistic work.

The third methodology considered only performing routine work when a block of five adjacent sections were degraded, this significantly reduced the number of interventions that were performed, thus in turn reduced the number of renewals that were required which significantly reduced the overall cost. There was however, a decrease in the amount of time spent in 'Good' condition and an increase in the proportion of time spent in 'Satisfactory' and 'Poor' condition.

The final method considered scheduling maintenance using work banks. By using work banks the final method was able to; vary the number of sections maintained during an intervention, allow maintenance to be performed despite the section being in 'Good' condition and 
prioritize sections in the worst condition. As work was permitted even if the alignment was 'Good' this methodology has the highest amount of tamping. It should be noted that in all cases emergency work was scheduled in the same way and therefore in all four methods there was no significant variation in the number of days with a speed restriction.

Of the four methodologies, method three was found to be the most cost effective, but method four is thought to be the best approximation of real life practices. In this study penalty costs are only introduced for 'Very Poor' and 'Super Red' conditions. There is no cost disadvantage to increasing the amount of time spent in 'Satisfactory' or 'Poor' condition rather than 'Good', however in reality this may not necessarily be the case.

As a future study the authors would like to investigate the impacts of assigning penalty costs to being in 'Satisfactory' and 'Poor' conditions, explore more comprehensive rules for generating work banks and explore how varying the time between work bank updates affects the results.

\section{Acknowledgements}

John Andrews is the Royal Academy of Engineering and Network Rail Professor of Infrastructure Asset Management. $\mathrm{He}$ is also Director of the Lloyd's Register Foundation Resilience Engineering Research Group. Jack Litherland is a Research Associate in Railway Infrastructure Asset Management. The authors greatly acknowledge the support of these organizations.

\section{Appendix A}

Deterioration distributions used in the Category 1A single track section model (Figure 5) (Audley and Andrews 2013)

\begin{tabular}{ccc}
\hline Transition & States & Distribution \\
\hline CT0 & Good & Weibull $(1500,0.95)$ \\
& $\rightarrow$ Satisfactory & \\
CT1 & $\begin{array}{c}\text { Satisfactory } \\
\rightarrow \text { Poor }\end{array}$ & Weibull $(2800,1.1)$ \\
& Poor $\rightarrow$ Very & Weibull $(3500,1.2)$ \\
CT2 & Poor & \\
& Very Poor & Weibull $(4000,1.4)$ \\
CT3 & $\rightarrow$ Super Red & \\
\hline
\end{tabular}

\section{References}

Alva-Hurtado, J. E., and E. T. Selig. 1981. "Permanent Strain Behavior of Railroad Ballast." In The 10th International Conference on Soil Mechanics and Foundation Engineering. Stockholm, Sweden.

Andrade, A. R., and P. F. Teixeira. 2015. "Statistical
Modelling of Railway Track Geometry Degradation Using Hierarchical Bayesian Models." Reliability Engineering and System Safety 142: 169-83.

Andrews, J. D. 2013. "A Modelling Approach to Railway Track Asset Management." Proceedings of the Institution of Mechanical Engineers, Part F: Journal of Rail and Rapid Transit 227 (1): 56-73.

Audley, M., and J. D. Andrews. 2013. "The Effects of Tamping on Railway Track Geometry Degradation." Proceedings of the Institution of Mechanical Engineers, Part F: Journal of Rail and Rapid Transit 227 (4): 376-91.

D'souza, S. K. 2017. “Asset Management of Offshore Oil and Gas Installations." PhD Thesis, University of Nottingham.

E. Selig and J. Waters. 1994. Track Geotechnology and Substruture Management. London: Thomas Telford.

Esveld, C. 2001. Modern Railway Track. 2nd ed. Zaltbommel: MRT-Productions.

Fecarotti, C., and J. D. Andrews. 2018. "Producing Effective Maintenance Strategies to Control Railway Risk." In Probabilistic Safety Assessment and Management PSAM 14. Los Angeles Califorina.

Lichtberger, B. 2007. "Das System Gleis Und Seine Instandhaltung." Der Eisenbahningenieur 58 (1).

Mahboob, Q. 2014. “A Bayesian Network Methodology for Railway Risk, Safety and Decision Support." PhD Thesis, Technische Universität Dresdon, Dersden.

Murata, T. 1989. "Petri Nets: Properties, Analysis and Applications." Proceedings of the IEEE 77 (4): 541-80.

Network Rail. 2012. "Network Rail Standards; Track Geometry - Inspections and Minimum Actions NR/L2/TRK/001/Mod11.”

Office of Road and Rail (UK). 2018. "Passenger Rail Usage 2017-18 Q4 Statistical Release.” London: Office of Road and Rail.

Petri, C. A. 1962. "Kommunikation Mit Automaten." $\mathrm{PhD}$ Thesis, University of Bonn.

Shafahi, Y., and R. Hakhamaneshi. 2009. "Application of a Maintenance Management Model for Iranian Railways Based on the Markov Chain and Probabilistic Dynamic Programming." Scientia Iranica 16 (1): 87-97. 